\title{
The Relationship between Vitamin D Levels and Clinical Outcomes of Neonatal Sepsis in Haji Adam Malik Hospital Medan, Indonesia
}

\author{
Kamsiah Kamsiah (D), Beby Syofiani Hasibuan* (D), Karina Sugih Arto (D) \\ Department of Child Health, Faculty of Medicine, Universitas Sumatera Utara, Medan, Indonesia
}

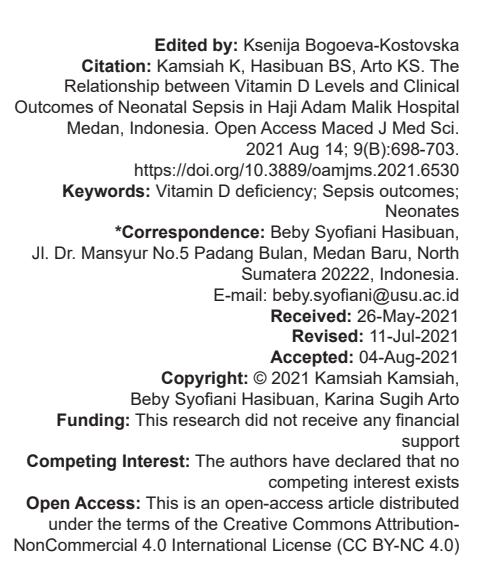

Introduction

Neonatal sepsis is an invasive bloodstream infection, with or without bacteremia, that occurs in neonates within the $1^{\text {st }}$ month of life. It is an important cause of neonatal morbidity and mortality. In addition, other clinical outcomes, such as respiratory support requirement, length of hospital stay, and respiratory distress, can be caused by neonatal sepsis. The study done by Levit et al., (2014) in the United States reported that the need of intubation or breathing aid was associated with mortality in neonatal sepsis [1]. In 2015, Haji Adam Malik Hospital, Medan recorded 154 (25.6\%) sepsis patients, with $79(51.3 \%)$ early-onset sepsis and $75(48.7 \%)$ late-onset sepsis cases among 626 neonates admitted [2].

Bacteria removal is the main option in the management of neonatal sepsis. Therefore, neonatal sepsis patients need to be treated as early as possible to prevent the unwanted outcomes, which can be longer hospital stay, respiratory problems including respiratory distress, ventilatory support requirements, and even death [1]. The deficiency in Vitamin $\mathrm{D}$ is correlated with the incidence of upper and lower respiratory tract infections by various causes, especially viruses and sepsis. Hasan et al., (2017) in their study in Iran reported a significant relationship between Vitamin D levels and respiratory distress syndrome in neonates [3].

Vitamin $D$ is one of the fat-soluble Vitamins. It regulates calcium and phosphor in the bone mineralization process [4]. Besides the classic functions, Vitamin $D$ also plays an important role in the immunity system [5]. Casecontrol study by Kanth et al., (2016) in India on pre-term and full-term neonates with earlyonset sepsis found that these babies had significantly lower levels of 25(OH)2-D that control group (14.69 $\pm 4.45 \mathrm{ng} / \mathrm{ml}$ and $26.46 \pm 22.01 \mathrm{ng} / \mathrm{ml} ; \mathrm{p}<0.01$ ) [6] A prospective study in Dublin by Onwuneme et al., (2015) done to 94 pre-term neonates with<32 weeks gestational age and $<1500 \mathrm{~g}$ birth weight reported $92 \%$ neonates with $\leq 20 \mathrm{ng} / \mathrm{mL}$ Vitamin D levels. Meanwhile, $64 \%$ neonates with $<12 \mathrm{ng} / \mathrm{mL}$ Vitamin D levels showed significant increases in supplemental oxygen use ( $p=$ $0.008)$, mechanical ventilation requirement and duration ( $p=0.013$ and $p=0.032$ respectively) [7]. Neonates begin receiving Vitamin $D$ in the womb through the placenta. Vitamin $D$ levels in maternal serum greatly affect the levels in the fetus. Low Vitamin D levels in mothers have a negative impact on the children's growth and development [8], as well as the immunity 
system [5]. The immunity system in neonates actually undergoes a transition process at birth, which occurs on a highly protected intrauterine to the extrauterine environment. During the transition process, the adaptive immune system has yet fully developed, therefore, the neonates are heavily dependant on innate immunity to protect them against pathogenic microbe invasion [9].

Vitamin $D$ plays a role in innate/non-specific and adaptive (acquired/specific) immune systems in neonates. It also increases innate (non-specific) immune responses by inducing cathelicidin (LL-37) - an endogenous antimicrobial peptide produced by macrophages and neutrophils. Thus, Vitamin D levels are suspected to be associated with LL-37 production, which plays an important role in the immune responses towards infections in neonates. Meanwhile, Vitamin D adaptive immune system responds to Th1, Th2, and $\beta$ cell functions [6].

There are not many studies about Vitamin D levels and outcomes of neonatal sepsis. In Indonesia, especially Haji Adam Malik Hospital, Medan, has never conducted research to examine the relationship between Vitamin $D$ and neonatal sepsis. This research was conducted to assess the relationship between Vitamin D and the outcomes of neonatal sepsis, such as blood culture, the length of hospital stay, requirement of respiratory support, and mortality.

\section{Methods}

This research was an analytical study with a cross-sectional approach to assess the relationship between Vitamin D levels and the outcomes of neonatal sepsis in neonatology Haji Adam Malik Hospital, Medan from June 2019 to February 2020. Research samples were neonates admitted to neonatology Haji Adam Malik Hospital during the study period and met the inclusion and exclusion criteria. Inclusion criteria were neonates with sepsis, either proven or probable sepsis, and the parents or guardians were willing to give their consent to join the research. Exclusion criteria were neonates with multiple congenital anomalies, suspected or proven pulmonary embolism from chest X-ray, and signs of deep vein thrombosis such as swelling in the extremities. This research has received approval from the Health Research Ethics Committee of Medical Faculty, Universitas Sumatera Utara (No. 538/TGL/ KEPK FK USU-RSUP HAM/2019) and Haji Adam Malik Hospital, Medan (DP.02.01/V/2.2.1/1826/2020).

Before the study was started, parents and guardians of the research subjects were given explanation about the research and they signed informed consent. Interviews and data collected from the medical record were done to obtain demographic data of the neonates. Laboratory test was done to all new patients with suspected sepsis when they were treated in the neonatology for the first time, following the laboratory standard in Haji Adam Malik Hospital for total Liaison ${ }^{\circledR} 25-\mathrm{OH}$ Vitamin D and blood culture tests.

\section{Data analysis}

Collected data were processed and analyzed using a computerized software system Statistical Package for Social Sciences for Windows (SPSS), with a $95 \%$ confidence interval $(\mathrm{Cl})$ and significance level of $p<0.05$. Bivariate analysis was used to describe the characteristic of samples. Chi-square was used to identify the relationship between Vitamin $D$ levels and the outcomes of neonatal sepsis, while Fisher exact test was the alternative used when the Chi-square test did not fit well. The relationship between Vitamin D levels and the length of hospital stay was assessed using Mann-Whitney test.

\section{Results}

\section{Research subject demographic characteristics}

There were 41 full and pre-term neonates who met the inclusion and exclusion criteria during the research period. From all research patients, 46.3\% (19/41) were male and $53.7 \%$ (22/41) were female. There were $60.9 \%$ (25/41) neonates with gestational age $<36$ weeks. Based on the birth weight, $17 \%(7 / 41)$ had very low birth weight, 43.9\% (18/41) had low birth weight, and 39\% (16/41) had normal birth weight. From blood culture test, there were $34.1 \%$ (14/41) neonates with positive culture, while the rest $65.9 \%$ (27/41) had negative culture. Vitamin D deficiency was observed in $75.6 \%$ (31/41) neonates, and only $24.4 \%$ (10/41) neonates with normal Vitamin $D$ levels were recorded. The average length of hospital stay was 21 days (ranging from 4 to 80 days). Death involved during the study was $17 \%$ (7/41), whereas $82.9 \%$ (34/41) neonates were discharged after treatment. Most neonates used CPAP $(46.3 \%, 19 / 41)$ and followed by ventilator uses $(34.1 \%, 14 / 41)$, whereas $19.5 \%$ (8/41) did not require respiratory support. The demographic characteristics of research subject are presented in Table 1.

\section{The relationship between Vitamin D levels and neonatal sepsis outcomes}

Vitamin D level data were divided into two groups, such as normal (31/41) and the deficiency $(10 / 41)$ in Vitamin D. The outcomes of neonatal sepsis assessed were mortality, the requirement of respiratory support, length of stay, and blood culture. The 
Table 1: Demographic characteristic of research subject

\begin{tabular}{ll}
\hline Characteristic & Neonatal sepsis $(\mathrm{n}=41)$ \\
\hline Gender (n, \%) & $19(46.3)$ \\
$\quad$ Male & $22(53.7)$ \\
$\quad$ Female & \\
Gestational age, (n, \%) & $25(60.9)$ \\
$\quad<36$ weeks & $16(39.1)$ \\
$\quad>36$ weeks & \\
Birth weight, gram (n, \%) & $0(0)$ \\
$\quad<1000 \mathrm{~g}$ & $7(17.1)$ \\
$\quad 1000-1500 \mathrm{~g}$ & $18(43.9)$ \\
$>1500-2500 \mathrm{~g}$ & $16(39)$ \\
$\quad>2500 \mathrm{~g}$ & \\
Delivery process (n, \%) & $10(24.4)$ \\
$\quad$ Spontaneous vaginal & $31(75.6)$ \\
$\quad$ Sectio caesarea & \\
CRP value, (n, \%) & $23(56.1)$ \\
$\quad<1$ mg & $18(43.9)$ \\
$\quad>1$ mg & \\
Blood culture (n, \%) & $14(34.1)$ \\
$\quad$ Positive & $27(65.9)$ \\
$\quad$ Negative & \\
Vitamin D deficiency, (n, \%) & $31(75.6)$ \\
$\quad$ Yes & $10(24.4)$ \\
$\quad$ No & \\
Outcomes, (n, \%) & $34(82.9)$ \\
$\quad$ Death & $7(17.1)$ \\
Alive & $21(4-80)$ \\
Length of stay, day & \\
median (range) & \\
Respiratory support (n, \%) & \\
$\quad$ No support required & $14(34.1)$ \\
Ventilator & $19(46.3)$ \\
CPAP &
\end{tabular}

relationships between Vitamin $D$ levels and neonatal sepsis outcomes were presented in Table 2.

Table 2: Vitamin D levels and neonatal sepsis outcomes

\begin{tabular}{llll}
\hline Neonatal sepsis outcomes & \multicolumn{2}{l}{ Vitamin D deficiency } & p \\
\cline { 2 - 3 } & \multicolumn{1}{l}{ Yes $(\mathrm{n}=31)$} & No $(\mathrm{n}=10)$ & \\
\hline Mortaliy, $\mathrm{n}(\%)$ & $6(19.4)$ & $1(10)$ & \\
$\quad$ Death & $25(80.6)$ & $9(90)$ & \\
$\quad$ Alive & $13(41.9)$ & $1(10)$ & $0.010^{\mathrm{b}}$ \\
Respiratory suppot, $\mathrm{n}(\%)$ & $15(48.4)$ & $4(40)$ & \\
$\quad$ Ventilator & $3(9.7)$ & $5(50)$ & \\
$\quad$ CPAP & $21(5-80)$ & $22.5(4-63)$ & $0.940^{\mathrm{c}}$ \\
$\quad$ No support required & $10(32.3)$ & $4(40)$ & $0.712^{\mathrm{a}}$ \\
$\quad$ Length of stay, median (range) & $21(67.7)$ & $6(60)$ & \\
Blood culture, $\mathrm{n}(\%)$ & & \\
$\quad$ Positive & & \\
$\quad$ Negative & &
\end{tabular}

The mortality rates in Vitamin $\mathrm{D}$ deficiency group were $19.4 \%(6 / 31)$ and only one death was recorded in the normal group $(1 / 10)$. Whereas, patients who lived and discharged after completion of treatment were 80.6\% (25/31) and 90\% (9/10) in Vitamin D deficiency and normal groups. respectively. Statistical test result analysis gave $\mathrm{p}=0.660(95 \% \mathrm{Cl}=0.810-1.677)$. There was no correlation between Vitamin D level and mortality in this study for neonatal sepsis.

The need of respiratory support was divided into three groups as follows: ventilator, CPAP, and no requirement. In Vitamin D deficiency group, $41.9 \%$ (13/31) neonates used ventilator, $48.4 \%(15 / 31)$ used CPAP tool and $9.7 \%(3 / 31)$ did not require breathing support. While in normal Vitamin D group, 10\% (1/10) used ventilator, $40 \%(4 / 10)$ needed CPAP, and 50\% (5/10) did not require breathing support during treatment. Statistical test result obtained was $0.013(p<0.05)$, therefore, Vitamin D levels were correlated to the need of respiratory support.

Another outcome assessed was the length of hospital stay. The median duration of hospital stay was 21 days (5-80 day range) and 22.5 (4-63 day) in Vitamin $D$ deficiency and normal groups respectively. Statistical test showed $p=0.940$, which can be concluded that there was no relationship between Vitamin $D$ levels and the length of hospital stay.

In blood culture assessment, $32.3 \%$ (10/31) positive blood cultures came from the deficiency Vitamin $D$ group, while $40 \%$ (4/10) were from normal Vitamin $D$ level group. Statistical test showed $p=0.712(95 \%$ $\mathrm{Cl}=0.623-1.353)$. Therefore, the relationship between Vitamin $\mathrm{D}$ levels and blood culture was insignificant.

\section{Discussion}

The roles of Vitamin $D$ in the immune system have triggered more research about Vitamin $D$ levels and the relationship with neonatal sepsis incidence. Premature babies are at risk of Vitamin D deficiency compared to full-term babies [10]. The study done by Park et al., (2015) in Korea to 278 premature babies reported $98.9 \%$ were deficient in Vitamin D and $51.1 \%$ were severely deficient [10]. In 2014, Heather et al., (2014) conducted their study in Boston and reported lower rates of Vitamin $D$ deficiency in premature babies [11]. In this study, however, $25(\mathrm{OH})$-D serum levels in full and pre-term babies were not separately recorded. The concentration of $25(\mathrm{OH})$-D serum levels in neonates is positively correlated with maternal 25(OH)-D serum concentration during pregnancy. Park et al., (2015) in their study in Korea reported lower $25(\mathrm{OH})-\mathrm{D}$ concentration in babies $(10 \mathrm{ng} / \mathrm{mL})$ than in Northern European Countries [10], including Norwegia (12.2 $\pm 5.5 \mathrm{ng} / \mathrm{mL})$ [12], and Finlandia $(11.7 \pm 4.7 \mathrm{ng} / \mathrm{mL})$ [13]. This could happen as maternal Vitamin D levels were affected by race, regions, genetics, and season changes [13]. Vitamin D levels also affected gestational age and birth weight of neonates $[6,14]$. In this study, $60.9 \%(25 / 41)$ of neonates with sepsis was at $<36$ weeks gestation, and $43.9 \%$ (18/41) were born with low birth weight $(>1500-2500 \mathrm{~g})$.

Vitamin $D$ deficiency in neonates was correlated with neonatal sepsis incidence [15]. In several pediatrics studies, significant relationships were reported between Vitamin D deficiency and sepsis [16]. Kanth et al., (2016) reported the majority of neonates $(64.1 \%)$ with neonatal sepsis were suffering from Vitamin $D$ deficiency, and Vitamin $D$ was statistically significant to neonatal sepsis $(p=0.05)$ [6]. Vitamin D roles in neonatal sepsis refer to clinical and bacteremia-related signs and symptoms that occur in the $1^{\text {st }}$ month of life; the occurrence is related to Vitamin $D$ receptors in the cellular immune system. The regulation of pathogenic microbes and TLRs by Vitamin D were expressed by signaling proteins, hence triggering monocytes, macrophages and neutrophils, and increasing 
chemotaxis, phagocytes, and bactericidal activities in the innate immune system. Another important role of Vitamin $D$ is also to induce cathelicidin - an important anti-microbial peptide that can directly inhibit the growth of Gram-positive and Gram-negative bacteria [17].

A casecontrol study done by Sarwade et al., (2019) in India to 60 Vitamin D deficient neonates with sepsis reported $66 \%$ positive culture blood test ( $p \leq 0.001$ ) [18]. The study done in Turkey by Terek et al., (2018) to 394 neonates showed positive and negative gram cultures were not significantly correlated to Vitamin D levels [14]. This result was aligned with this study, where blood culture was not significantly correlated to Vitamin D level, with $p>0.05$. Another study by Hollick et al., (2011) to 117 neonates also reported insignificant difference between Vitamin D leves and neonatal sepsis from blood culture result [19]. Diagnosis of neonatal sepsis can be enforced only by looking at clinical condition, and with or without bacteremia.

The incidence rate of sepsis in developing countries is pretty high ad 1.8-18/1000 live births, with $12-68 \%$ mortality rate. Meanwhile, industrialized countries reported 3 sepsis cases per 1000 live births and $10.3 \%$ mortality rate. In Indonesia, the mortality rate of neonatal sepsis reached $14 \%$ in the year 2013 [20]. A cohort study by Braun et al., (2011) in Boston stated that death occurred when Vitamin D level was $<32 \mathrm{nmol} / \mathrm{L}$, and no death was recorded when Vitamin D level was higher than $65 \mathrm{nmol} / \mathrm{L}$ [21]. The Institute of Medicine (US) Committee reported an inverse J-form relationship between $25(\mathrm{OH})$-D and all causes of mortality. This showed that too high of Vitamin $\mathrm{D}$ levels would be toxic to neonates, while too low would lead to unwanted outcomes. 25(OH)-D serum at 50-60 $\mathrm{nmol} / \mathrm{L}$ had low risk of mortality [22]. A meta-analysis study done by Mukhopadhyay and Puopolo (2012) in Boston reported similar result, where Vitamin $D$ level below 50 nmol/L increased mortality risk [23]. However, mortality and Vitamin D levels were not correlated in this study, with $p>0.05$. This is because the neonates with $>36$ weeks gestation were not excluded. While, low birth weight and a history of severe asphyxia risk factors, which facilitate infections with cell injuries from hypoxia and trigger inflammation to deaths, are not found in neonates with $>36$ weeks gestation.

The effect of Vitamin D on lung development is an important issue that has been much researched about recently. A few studies reported different results, where the studies done by Ozdemir et al., (2018) [24] in Turkey and Onwuneme et al., (2015) [7] in Dublin reported no correlation between Vitamin $D$ and neonatal sepsis or respiratory distress, NEC, intraventricular bleeding and death. However, the study done by Lykkedegn et al., (2015) in Denmark stated that deficiency in Vitamin D in pregnant mothers affected fetal growth and development and led to low birth weight and premature births; in which all of them may have impact on respiratory distress and increase in bronchopulmonary dysplasia [25]. Moreover, the prospective study done by Catinkaya et al., (2015) in Turkey to 81 pre-term neonates showed significant relationship between Vitamin D levels below $15 \mathrm{ng} / \mathrm{mL}$ and increased risk of respiratory disorders, including respiratory distress [9]. The deficiency in Vitamin D is related with risk of bad fetal growth, in which Vitamin D affect fetal development and growth during pregnancy and the deficiency is a risk factor in developmental disorders of many organs in neonates [7].

The need of respiratory support, both invasive or non-invasive, often becomes the risk factor for neonatal sepsis [9]. The study by Onwuneme et al., (2015) to 94 neonates reported $25(\mathrm{OH})-\mathrm{D}$ concentration $<30 \mathrm{nmol} / \mathrm{L}$ (12 ng/mL) in newborns increases the need of oxygen ( $p=0.008)$, as well as the increase of mechanical ventilator and the length of use $(p=0.013)$ [7]. Similarly, our study showed correlation between Vitamin $D$ levels and the use of respiratory support as one of the outcomes of neonatal sepsis. A retrospective study done by Shah et al., (2015) to 7509 neonates found babies with late onset sepsis significantly increased the length of stay and requirement of breathing support [26].

Vitamin $D$ deficiency also inhibits the maturation of macrophages, therefore, reducing the production of lysozyme and $\mathrm{H}_{2} \mathrm{O}_{2}$ that have antimicrobial effects. Moraes et al., (2015) in their study in Sao Paolo reported the correlation of Vitamin $D$ deficiency with the increase in length of stay, mechanical ventilation needs, and fluid and inotropic resuscitation in sepsis patients [27]. However, this report was not align with the cross-sectional analytical research in Padang, Indonesia by Nice and Indra (2017) done to 56 critically ill children reported no significant differences between Vitamin D with the length of hospital stay, although there were differences of the length of stay in the group that survived [28]. In this research, using the Mann-Whitney test, no significant relationship was observed between Vitamin D and length of hospital stay.

The status of Vitamin D in neonates is due to many factors, one of them because of the mothers as the source of Vitamin $D$ in neonates. When a mother was Vitamin $D$ deficient, it would affect not only the mother but also the neonate she was carrying [29]. The Institute of Medicine has pointed out the need of at least 400-600 IU/day Vitamin D intake in pregnant women. In Turkey, 50-94\% of pregnant women were reported to suffer from Vitamin $D$ deficiency, therefore, they were given 1200 IU/day Vitamin D supplementation [24]. The study done by Ozdemir et al., (2018) in Turkey reported only $14.4 \%$ of pregnant women took $1000-1200$ IU/day of Vitamin D. When the mother groups were evaluated in terms of risk factors, there were significant differences in daily vitamin intake and clothing style. Whereas, only $27 \%$ of neonates with Vitamin D deficiency were born from mothers who received Vitamin $D$ supplements during pregnancy $(p<0.001$ and $p<0.001$, 
respectively) [24]. Similar results were also reported by the study done by Cizmeci et al., (2014) in Turkey [30]. In this study, however, maternal Vitamin D levels were not assessed because not all neonates involved in the study were born in Haji Adam Malik hospital.

\section{Conclusion}

The results of this study showed that Vitamin D levels were positively correlated to the requirement and use of ventilatory support. Whereas, other outcomes such as mortality, length of hospital stay, and blood culture did not have a significant relationship with Vitamin D levels.

\section{References}

1. Levit O, Bhandari V, Li FY, Shabanova V, Gallagher PG, Bizzarro MJ. Clinical and laboratory factors that predict death in very low birthweight infants presenting with late-onset sepsis. Pediatr Infect Dis J 2014;33(2):143-6. https://doi.org/10.1097/ inf.0000000000000024

PMid:24418836

2. Hasibuan BS. Comparison of Microbial Pattern in Early and Late Onset Neonatal Sepsis in Referral Center Haji Adam Malik Hospital Medan Indonesia. Vol. 125. Dalam: Earth and Environmental Science; 2018. p. 1-5. https://doi. org/10.1088/1755-1315/125/1/012053

3. Hasan B, Gholamali M, Seyedeh FK, Faramarzi R. Serum level of Vitamin $D$ in preterm infants and its association with premature-related respiratory complications: A casecontrol study. Ephysician. 2017;10(1):6208-14. https://doi. org/10.19082/6208

PMid:29588821

4. Sjarif DR, Lestari ED, Mexitalia M, Nasar SS. Pediatric Nutrition and Metabolic Disease Textbook. Indonesian Pediatric Association. 2014;1(2):188-95.

5. Clancy N, Onwuneme C, Carroll A, McCarthy R, McKenna MJ, Murphy $\mathrm{N}$, et al. Vitamin $\mathrm{D}$ and neonatal immune function. J Matern Fetal Neonatal Med. 2012;26(7):639-46. https://doi. org/10.3109/14767058.2012.746304

PMid:23131172

6. Kanth SU, Reddy KA, Abhishek GS. Association between Vitamin $D$ levels and early onset sepsis in infants: A prospective observational study. Int J Contemp Pediatr. 2016;3(4):1189-92. https://doi.org/10.18203/2349-3291.ijcp20163168

7. Onwuneme C, Martin F, McCarthy R, et al. The associationof Vitamin $D$ status with acute respiratory morbidity in preterm infants. J Pediatr 2015;166:1175-80.e1.

PMid:25919726

8. Koumi MA, Ali YF, El Rahman RN. Impact of maternal Vitamin D status during pregnancy on neonatal Vitamin D status. Turk $J$ Pediatr. 2013;55(4):371-7. https://doi.org/10.4081/pr.2013.e6 PMid:24292029

9. Catinkaya M, Cekmiz F, Buyukkali E, Erener-Ercan T, Demir F, Tunc T, et al. Lower Vitamin D levels are associated with increased risk of early-onset neonatal sepsis in term infants. J Perinatol. 2015;35(1):39-45. https://doi.org/10.1038/ jp.2014.146

PMid:25102323

10. Park SH, Lee GM, Moon JE, Kim HM. Severe Vitamin D deficiency in preterm infants: Maternal and neonatal clinical features. Korean J Pediatr. 2015;58(11):427-33. https://doi. org/10.3345/kjp.2015.58.11.427 PMid:26692878

11. Heather HB, Linda JVM, Thomas FM, Tabatabai P, Litonjua AA, Weiss ST, et al. Vitamin D status among preterm and full-term infants at birth. Pediatr Res. 2014;75(1-1):75-80. https://doi. org/10.1038/pr.2013.174

PMid:24121425

12. Markestad T, Aksnes L, Finne PH, Aarskog D. Vitamin D nutritional status of premature infants supplemented with $500 \mathrm{IU}$ Vitamin D2 per day. Acta Paediatr Scand. 1983;72(4):517-20. https://doi.org/10.1111/j.1651-2227.1983.tb09763.x PMid:6605019

13. Backstrom MC, Maki R, Kuusela AL, Sievänen $H$, Koivisto AM, Ikonen RS, et al. Randomised controlled trial of Vitamin D supplementation on bone density and biochemical indices in preterm infants. Arch Dis Child Fetal Neonatal Ed. 1999;80(3):F161-6. https://doi.org/10.1136/fn.80.3.f161 PMid: 10212074

14. Terek D, Oscan G, Ergin F, Koroglu OA, Yalaz M, Akisu M, et al. Vitamin D deficiency in premature infants and its effects on neonatal prognosis. J Pediatr Res Turk. 2018;5(1):37-40. https://doi.org/10.4274/jpr.82788

15. Dhandai R, Jajoo M, Sigh A, Mandal A, Jain R. Association of Vitamin $D$ deficiency with an increased risk of late-onset neonatal xepsis. Paediatr Int Child Health. 2018;38(3):193-7. https://doi.org/10.1080/20469047.2018.1477388 PMid:30003852

16. Austin ST, Yoel C, Lubis M. 25-hydroxyvitamin D level as sepsis marker in children. Sari Pediatr. 2017;19(3):150-5. https://doi. org/10.14238/sp19.3.2017.150-5

17. Florentina, Treszlb A, Hajdúa J, Toldi G, Rigó J Jr., Tulassay T, et al. Plasma Vitamin D levels at birth and immune status of preterm infants. Immunobiology. 2016;221(11):1289-92. https:// doi.org/10.1016/j.imbio.2016.06.001 PMid:27318428

18. Sarwade BA, Gosai MM, Gohil RJ. Vitamin D levels in early onset neonatal sepsis without maternal risk factors: A casecontrol study. Vitam Miner. 2019;8:1-5.

19. Holick MF, Binkley NC, Bischoff-Ferrari HA, Gordon CM, Hanley DA, Heaney RP, et al. Evaluation, treatment, and prevention of Vitamin D deficiency: An endocrine society clinical practice guideline. J Clin Endocrinol Metab. 2011;96(7):1911-30. https://doi.org/10.1210/jc.2011-0385 PMid:21646368

20. Kosim MS, Yunanto A, Dewi R, Sarosa GI, Usman A. Neonatology Textbook. Vol.4. Jakarta:Indonesian Pediatric Association:2014.p.170-7.

21. Braun A, Chang D, Mahadevappa K. Association of low serum 25-hydroxyvitamin D levels and mortality in the critically ill. Crit Care Med. 2011;39(4):671-7. https://doi.org/10.1097/ ccm.0b013e318206ccdf PMid:21242800

22. National Academies Press. Institute of medicine (US) committee to review Dietary reference intakes for Vitamin $D$ and calcium. In: Ross AC, Taylor CL, Yaktine AL, Del Valle HB, editors. Dietary Reference Intakes for Vitamin D and Calcium. Washington, DC: National Academies Press; 2011. https://doi.org/10.1108/ nfs.2012.42.2.131.2 
23. Mukhopadhyay S, Puopolo KM. Risk assessment in neonatal early sepsis. Semin Perinat. 2012;36(6):408-15.

PMid:23177799

24. Ozdemir AA, Ercan Gundemir Y, Kucuk M, Sarıcı DY, Elgörmüş Y, Çağ $Y$, et al. Vitamin D deficiency in pregnant women and their infants. J Clin Res Pediatr Endocrinol. 2018;10(1):44-50. https:// doi.org/10.4274/jcrpe.4706

PMid:28901944

25. Lykkedegn S, Sorensen GL, Beck-Nielsen SS, Christesen HT. The impact of Vitamin $D$ on fetal andneonatal lung maturation. A systematic review. Am J Physiol Lung Cell Mol Physiol. 2015;308(7):587-602. https://doi.org/10.1152/ ajplung.00117.2014

PMid:25595644

26. Shah J, Jefferies AL, Yoon EW, Lee SK, Shah PS, Canadian Neonatal Network. Risk factors and outcomes of late-onset bacterialsepsis in preterm neonates born at $<32$ weeks' gestation. Am J Perinatol 2015;32(7):675-82. https://doi. org/10.1055/s-0034-1393936

PMid:25486288
27. Moraes RB, Friedman G, Wawrzeniak LW, Marques LS, Nagel FM, Lisboa TC, et al. Vitamin D deficiency is independently associated with mortality among critically ill patients. Clinics Sao Paulo. 2015;70(5):326-32. https://doi.org/10.6061/ clinics/2015(05)04

PMid:26039948

28. Nice RM, Indra I. The relationship between vitamin D status with mortality and length of hospital stay in critically ill children. Jurnalmka.2017;40:82-9. https://doi.org/10.22338/mka.v40. i2.p82-89.2017

29. Herrmann M, Farrell CJ, Pusceddu I, Fabregat-Cabello N Assessment of Vitamin D status a changing landscape. Clin Chem Lab Med 2017;55(1):3-26. https://doi.org/10.1515/ cclm-2016-0264

PMid:27362963

30. Cizmeci MN, Kanburoglu MK, Akelma AZ, et al. Cord-blood 25-hydroxyvitamin $D$ levels and risk of early-onset neonatal sepsis: A case-control study from a tertiary care center in Turkey. Eur J Pediatr. 2014;82:310-2. https://doi.org/10.1007/ s00431-014-2469-1 